\title{
Granulometria do milho em rações para juvenis de tambaqui
}

\author{
Corn granulometry in diets for tambaqui juvenile
}

\author{
PEREIRA, Samuel Louzada ${ }^{1 *}$; GONÇALVES JÚNIOR, Lucas Pedro²; AZEVEDO, \\ Rafael Vieira de ${ }^{3}$; MATIELO, Marcelo Darós ${ }^{2}$; POLESE, Marcelo Fanttini ${ }^{4}$; \\ MENDONÇA, Pedro Pierro ${ }^{5}$
}

\footnotetext{
${ }^{1}$ Universidade Estadual do Norte Fluminense Darcy Ribeiro, Centro de Ciências e Tecnologias Agropecuárias, Laboratório de Zootecnia e Nutrição Animal, Campos dos Goytacazes, Rio de Janeiro, Brasil.

${ }^{2}$ Universidade Federal do Espírito Santo. Alegre, Espírito Santo, Brasil.

${ }^{3}$ Instituto Capixaba de Pesquisa, Assistência Técnica e Extensão Rural, Ibiraçu, Espírito Santo, Brasil.

${ }^{4}$ Instituto Federal do Espírito Santo, Alegre, Espírito Santo, Brasil.

${ }^{5}$ Instituto Federal do Espírito Santo, Piúma, Espírito Santo, Brasil.

*Endereço para correspondência: samuell_lp@hotmail.com
}

\section{RESUMO}

Objetivou-se avaliar diferentes granulometrias do milho (GM) em rações para juvenis de tambaqui sobre o desempenho zootécnico, composição da carcaça e viabilidade econômica. Foram distribuídos 160 peixes $(3,86 \pm 0,03 \mathrm{~g})$ em 20 aquários $(40 \mathrm{~L})$, em delineamento inteiramente casualizado com cinco tratamentos e quatro repetições. Os tratamentos consistiram de rações com diferentes GM: 150, 300, 500, 710 e $850 \mu \mathrm{m}$. Como parâmetros de desempenho zootécnico foram avaliados: consumo de ração (CR), ganho de peso (GP), conversão alimentar (CA), comprimento total final $(\mathrm{CTF})$, comprimento padrão final $(\mathrm{CPF})$, altura final (ALT), taxa de crescimento específico (TCE), taxa de desenvolvimento específico (TDE) e sobrevivência (SOB). Para composição de carcaça foram avaliados umidade, proteína bruta, extrato etéreo e matéria mineral. Na análise econômica das rações, foram analisados o custo médio com ração por quilograma de peso vivo ganho (CMR), o custo total de produção (CTP) e o índice de eficiência econômica (IEE). Os dados obtidos foram submetidos à análise de variância em nível de $5 \%$ de probabilidade e regressão polinomial. Verificou-se comportamento quadrático para as variáveis CR, GP, CA, TCE, TDE, CTF, CPF e ALT, obtendo-se os melhores resultados, respectivamente, para GM estimadas em 530,$22 ; 555,40 ; 597,47 ; 566,75 ; 562,07 ; 557,48$; 562,70 e $555,68 \mu \mathrm{m}$. Não houve influência das GM sobre a composição da carcaça. Verificouse comportamento quadrático para as variáveis
CTP e CMR, com valores mais altos para GM estimadas em, respectivamente, 600,44 e 602,11 $\mu \mathrm{m}$. Conclui-se que granulometria do milho de $500 \mu \mathrm{m}$ é indicada zootecnicamente e economicamente para rações de juvenis de tambaqui.

Palavras-chave: avaliação econômica, Colossoma macropomum, nutrição de peixes, peixe nativo

\section{SUMMARY}

This study aimed to evaluate the performance, carcass composition and viability of different corn granulometry (CG) in diets for tambaqui. It was distributed 160 fish $(3.86 \pm 0.03 \mathrm{~g})$ into 20 aquaria (40-L) in a completely randomized design with five treatments and four replications. The treatments consisted of diets with different CG: 150, 300, 500, 710 and 850 $\mu \mathrm{m}$. As performance parameters were evaluated: feed intake (FI), weight gain (WG), feed conversion rate (FCR), final total length (FTL), final standard length (FSL), height $(\mathrm{H})$, specific growth rate (SGR), specific development rate (SDR) and survival (SUR). For carcass composition were evaluated moisture, crude protein, ether extract and mineral matter. For the economic analysis of diet were analyzed the total cost of production (TCP), cost of feed per $\mathrm{kg}$ weight gain (CFK) and the index of economic efficiency (IEE). Data were subjected to analysis of variance at $5 \%$ probability and 
Rev. Bras. Saúde Prod. Anim., Salvador, v.17, n.2, p.299-310 abr./jun., 2016 http://www.rbspa.ufba.br ISSN 15199940

polynomial regression. There was quadratic effect for the variables FI, WG, FCR, FTL, FSL, $\mathrm{H}$, SGR and SDR, obtaining the best results, respectively, for $\mathrm{CG}$ estimated at 530.22; $555.40 ; 597.47 ; 566.75 ; 562.07 ; 557.48 ; 562.70$ e $555.68 \mu \mathrm{m}$. There was no influence of CG on the carcass composition. There was quadratic effect for TCP and CFK variables, with higher values for $\mathrm{CG}$ estimated at, respectively, 600.44 and $602.11 \mu \mathrm{m}$. It is concluded that $\mathrm{CG}$ of 500 $\mu \mathrm{m}$ is indicated to tambaqui feed.

Keywords: economic evaluation, Colossoma macropomum, fish nutrition, native fish

\section{INTRODUÇÃO}

O tambaqui (Colossoma macropomum), pertencente à família Characidae e subfamília Serrasalminae, é o segundo maior peixe de escama da bacia amazônica, podendo atingir, na natureza, cerca de $1,0 \mathrm{~m}$ de comprimento total e mais de $30 \mathrm{~kg}$ de peso (ARAÚJO-LIMA \& GOULDING, 1998). Dentre as características desejáveis para criação em cativeiro, apresenta hábito alimentar onívoro, crescimento rápido, rusticidade, tolera baixos níveis de oxigênio dissolvido na água, apresenta fácil adaptação a diferentes sistemas de cultivo e alimentação artificial, além de técnicas de reprodução induzida já conhecidas (GRAEF， 1995; ARAÚJO-LIMA \& GOMES, 2005).

Os gastos com alimentação na piscicultura podem representar até $70 \%$ dos custos totais de produção (GUIMARÃES et al., 2008). Dessa forma, o estudo da composição e do processamento das rações de modo que promova redução nos custos de produção e potencialização da utilização dos ingredientes da dieta, é de grande importância (SENA et al., 2012; AZEVEDO et al., 2013; BRAGA et al., 2014).
A formulação de uma ração consiste em buscar o balanceamento dos nutrientes necessários para crescimento, mantença e sanidade dos animais (SANTOS et al., 2010). De igual modo, as rações devem ser processadas para apresentarem características físicas desejáveis. Segundo Meurer et al. (2005), no processamento de rações, o grau de moagem é um dos fatores mais importantes que altera a propriedade física dos peletes, dureza e seletividade por parte dos animais.

A granulometria dos ingredientes da ração pode influenciar na eficiência da digestão dos alimentos, pela superfície da exposição destes às secreções digestivas, bem como o tempo de passagem pelo trato gastrintestinal (NRC, 1993). Além desses fatores, um grau fino de moagem pode proporcionar boa estabilidade das rações peletizadas, diminuir a lixiviação dos nutrientes e aumentar a eficiência alimentar pelos peixes (MEURER et al., 2005; MAKINO et al., 2010).

Nesse sentido, objetivou-se avaliar o efeito da granulometria do milho em rações para juvenis de tambaqui sobre o desempenho zootécnico, composição de carcaça e índices econômicos.

\section{MATERIAL E MÉTODOS}

O experimento foi realizado no setor de Aquicultura do Instituto Federal de Educação Ciência e Tecnologia do Espírito Santo, situado em Alegre - ES, durante 50 dias. Para obtenção dos juvenis utilizados no experimento, matrizes de tambaqui foram submetidas a indução hormonal. Um lote com 500 juvenis de aproximadamente $3 \mathrm{~g}$ foi alojado em dois tanques de $500 \mathrm{~L}$, com recirculação de água, com a finalidade de uniformizar o lote e promover a 
Rev. Bras. Saúde Prod. Anim., Salvador, v.17, n.2, p.299-310 abr./jun., 2016 http://www.rbspa.ufba.br ISSN 15199940

adaptação às rotinas do laboratório por uma semana.

Um total de 160 juvenis de tambaqui, com medidas iniciais de peso, comprimento total, comprimento padrão e altura de, respectivamente, $3,86 \pm 0,03 \mathrm{~g}$, $6,00 \pm 0,01 \mathrm{~cm}, 4,61 \pm 0,02 \mathrm{~cm}$ e $2,42 \pm$ $0,01 \mathrm{~cm}$, foi distribuído em 20 aquários com volume útil de 40L, na densidade de oito peixes por aquário. As unidades experimentais eram providas de sistema de entrada e saída de água independentes, acopladas a um sistema de recirculação de água, com filtro mecânico e biológico. Os peixes passaram por período de adaptação de cinco dias às unidades experimentais.

O delineamento experimental utilizado foi inteiramente casualizado com cinco tratamentos e quatro repetições. Os tratamentos consistiram de rações com diferentes granulometrias do milho (150, $300,500,710$ e $850 \mu \mathrm{m})$, as quais foram obtidas por peneiramento, durante 10 minutos em vibrador de peneiras, do milho moído em moinho de martelo.

Para confecção das rações experimentais, os ingredientes foram homogeneizados em misturador tipo $\mathrm{Y}$, peletizados e, posteriormente, desidratados em estufa de ventilação forçada por 24 horas (Tabelas 1 e 2). Ao longo do período experimental, o monitoramento da qualidade da água foi feito com uso de oxímetro (DO - 5519, Lutron, Taipei, Taiwan), peagâmetro (PH100 Phtek, São Paulo, SP, Brasil) e condutivímetro (CD 4301, Lutron, Taipei, Taiwan) com os quais foram coletados

dados de temperatura, oxigênio dissolvido, $\mathrm{pH}$ e condutividade elétrica, cujos valores médios foram, respectivamente $\quad 27,77 \pm 0,04^{\circ} \mathrm{C}$, $5,25 \pm 0,33 \mathrm{mg} \mathrm{L}^{-1}, 6,96 \pm 0,07$ e $0,196 \pm 0,02$ $\mu \mathrm{S}$. Os peixes foram alimentados ad libitum três vezes ao dia, às 07:30, 12:00 e 16:00 horas. As rações, para cada repetição, foram pesadas no início e ao final do período experimental para calcular o consumo de alimento. Quando era observada alguma sobra de ração (intervalo de 20 minutos) após o manejo alimentar, estas eram coletadas, secas em estufa, posteriormente pesadas e os valores registrados para correção do consumo de ração.

Tabela 1. Composição das rações experimentais

\begin{tabular}{lc}
\hline Ingrediente & $\left(\mathrm{g} \mathrm{kg}^{-1}\right)$ \\
\hline Farinha de carne & 298,0 \\
Farelo de soja & 298,0 \\
Farelo de milho & 294,0 \\
Farinha de trigo & 50,0 \\
Óleo de soja & 50,0 \\
Premix mineral-vitamínico & 9,0 \\
Vitamina C & 1,0 \\
Metionina & 6,0 \\
\hline 'Premix (kg-1) - vit.A: 100.000UI; vit.D3: \\
32.000UI; vit.E: 240mg; vit.B1: 20mg; vit.B2: \\
61,4mg: vit.B6: 20mg; vit.B12: 320mg; vit.K3: \\
40mg; ácido fólico: 7,2mg; ácido pantotênico: \\
294mg; biotina: 1mg; cloreto de colina: 2000mg; \\
niacina: 396mg; L-lisina: 20g; Ca: 240mg; P: \\
78mg; Na: 60g; Co: 3,6mg; Cu: 4750mg; Fe: \\
2228mg; I: 7,32mg; Mn: 27mg; Se: 6,6mg; Zn: \\
2603mg; F: 780mg; antioxidante: 200mg.
\end{tabular}

Tabela 2. Composição bromatológica das rações experimentais

\begin{tabular}{lccccc}
\hline \multirow{2}{*}{ Composição analisada $\left(\mathrm{g} \mathrm{kg}^{-1}\right)^{1}$} & \multicolumn{5}{c}{ Granulometria do milho $(\mu \mathrm{m})$} \\
\cline { 2 - 6 } & 150 & 300 & 500 & 710 & 850 \\
\hline Matéria seca & 93,73 & 94,54 & 93,46 & 93,82 & 92,92 \\
Proteína bruta & 31,08 & 31,36 & 30,94 & 30,82 & 30,52 \\
Extrato etéreo & 3,68 & 4,21 & 4,13 & 4,17 & 4,46 \\
Matéria mineral & 15,98 & 16,34 & 16,05 & 16,29 & 16,18 \\
\hline
\end{tabular}

${ }^{1}$ Segundo Silva e Queiroz (2006) 
Rev. Bras. Saúde Prod. Anim., Salvador, v.17, n.2, p.299-310 abr./jun., 2016 http://www.rbspa.ufba.br

Após o término do período experimental, foi realizada biometria para obtenção dos valores finais de peso, comprimento e altura dos animais. Após a biometria, três peixes por repetição foram eutanaziados (superdosagem de Benzocaína 100ppm), eviscerados e congelados $\left(-25^{\circ} \mathrm{C}\right)$ para posteriores análises bromatológicas da carcaça.

Os parâmetros de desempenho zootécnico avaliados foram: consumo de ração, ganho de peso (peso final - peso inicial), conversão alimentar (consumo de ração/ganho de peso), comprimentos total e padrão finais, altura final, taxa de crescimento específico [(ln peso final ln peso inicial)/período experimental] $\mathrm{x}$ 100, taxa de desenvolvimento específico [(ln comprimento total final $-\ln$ comprimento total inicial)/período experimental] X 100 e sobrevivência (número final de peixes/número inicial de peixes) $x 100$.

Para realização das análises bromatológicas, as carcaças dos peixes foram descongeladas, trituradas, secas em estufa de ventilação forçada $\left(55^{\circ} \mathrm{C}\right)$ e moídas. As análises de umidade, proteína bruta, extrato etéreo e matéria mineral foram realizadas segundo Silva \& Queiroz (2006).

Para analisar a viabilidade econômica, foram coletados dados sobre o preço de ingredientes junto a fornecedores, com base nos preços de varejo, no entanto, estes valores foram convertidos para a moeda dólar (taxa de câmbio igual a $\mathrm{R} \$$ 3,09 no mês de junho de 2015).

Foram avaliados como índices de economia, a estimativa do custo total de produção utilizando-se apenas os parâmetros custo com a alimentação e o desempenho animal, o custo médio com ração por quilograma de peso vivo ganho e o índice de eficiência econômica segundo (SILVA et al., 2008).

Os dados obtidos foram submetidos à análise de variância (one-way ANOVA) a $5 \%$ de probabilidade e, em caso de diferença estatística, aplicou-se a análise de regressão, utilizando o software SAS 9.0. (SAS, 2001).

\section{RESULTADOS E DISCUSSÃO}

Não houve mortalidade durante o período experimental. Foi observada influência significativa da granulometria do milho sobre as variáveis de desempenho zootécnico avaliadas $(\mathrm{P}<0,05)$. Verificou-se comportamento quadrático para as variáveis consumo de ração, ganho de peso, conversão alimentar, taxa de crescimento específico, taxa de desenvolvimento específico, comprimento total final, comprimento padrão final e altura, obtendo-se os melhores resultados, respectivamente, para as granulometrias do milho estimadas em 530,22; 555,40; 597,$47 ; 566,75 ; 562,07 ; 557,47 ; 562,70$ e $555,68 \mu \mathrm{m}$ (Figuras 1, 2, 3, 4, 5, 6, 7 e 8). Corroborando com os resultados obtidos, Hayashi et al. (1999) avaliaram diferentes granulometrias do milho (500 e $1500 \mu \mathrm{m})$ em rações para tilápia do Nilo (Oreochromis niloticus) e observaram melhor desempenho zootécnico com a granulometria de $500 \mu \mathrm{m}$. Já Soares et al. (2003), avaliaram diferentes graus de moagem $(500,750,1000$, e $1500 \mu \mathrm{m})$ dos ingredientes de rações para a tilápia do Nilo e observaram efeito quadrático para as variáveis de desempenho e utilização do alimento, com melhores valores obtidos para a granulometria de $750 \mu \mathrm{m}$. Estes resultados podem ser explicados pela melhora na digestibilidade dos nutrientes. Nutricionalmente, o tamanho das partículas dos ingredientes destinados à fabricação de rações pode influenciar na digestibilidade dos nutrientes e, como consequência, no 
Rev. Bras. Saúde Prod. Anim., Salvador, v.17, n.2, p.299-310 abr./jun., 2016 http://www.rbspa.ufba.br ISSN 15199940

desempenho zootécnico (SOARES et al., 2003). Corroborando com essa afirmação, Zanotto et al. (1995) afirmaram que a granulometria dos ingredientes da ração afeta o consumo de alimento e a digestão dos ingredientes, pela alteração da anatomia e das secreções do trato digestório.

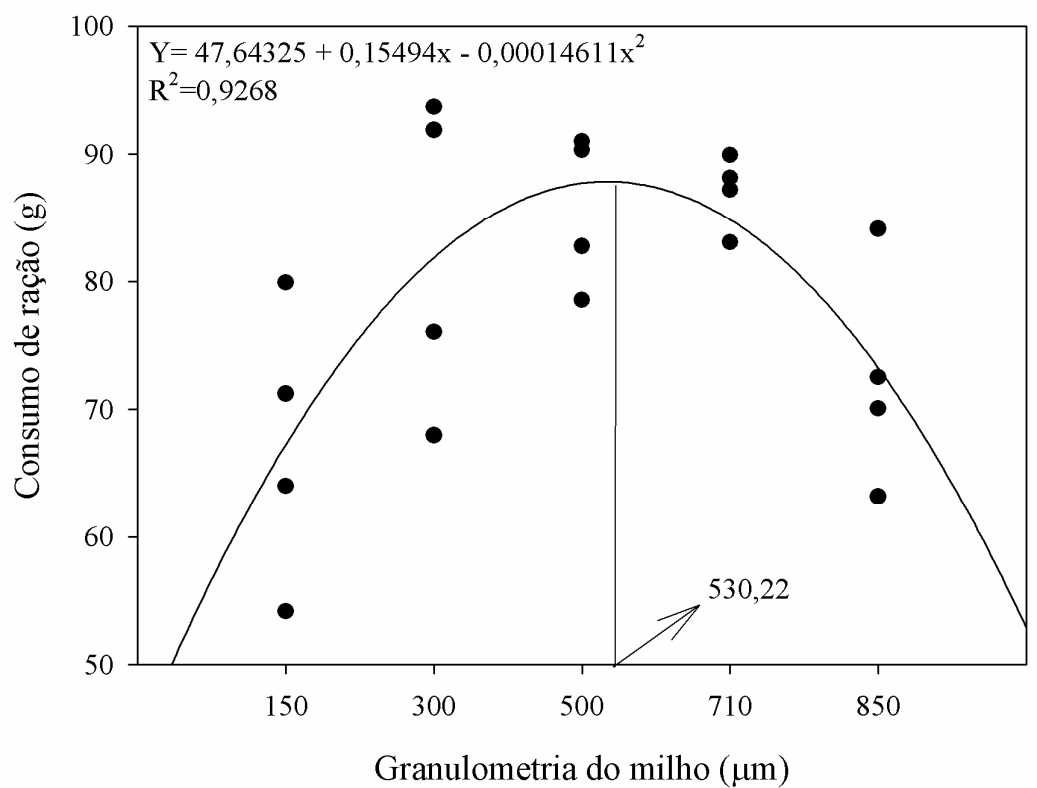

Figura 1. Efeito da granulometria do milho sobre o consumo de ração para juvenis de tambaqui

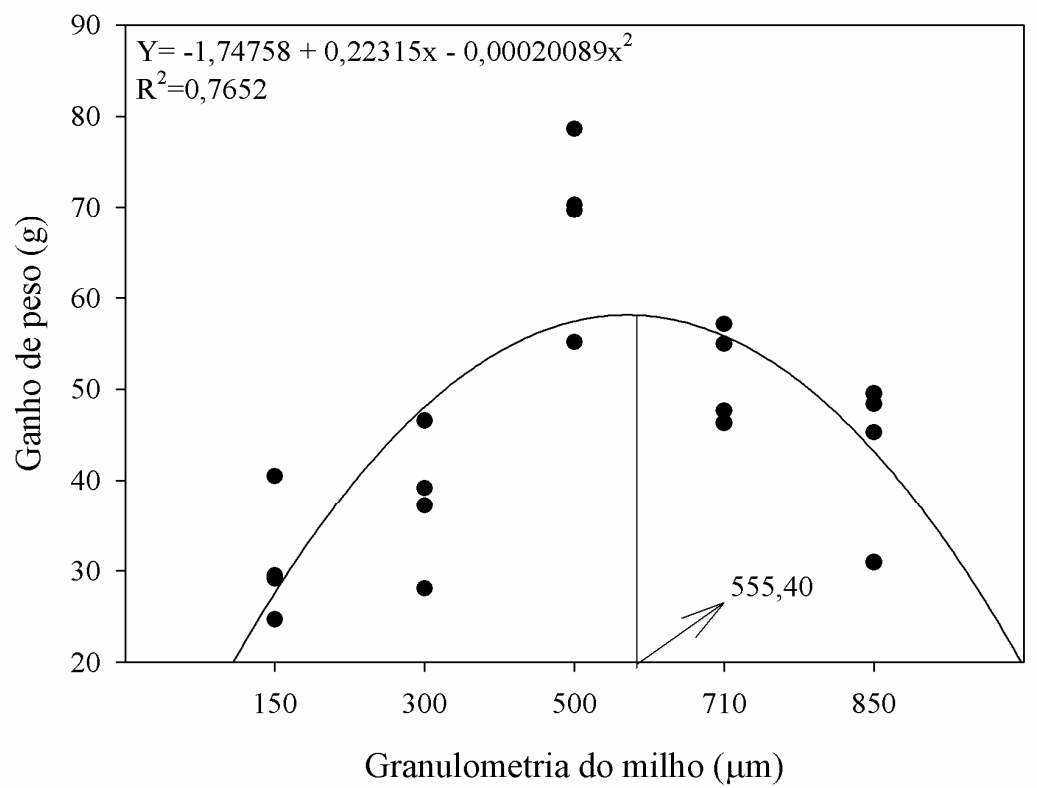

Figura 2. Efeito da granulometria do milho sobre o ganho de peso para juvenis de tambaqui 
Rev. Bras. Saúde Prod. Anim., Salvador, v.17, n.2, p.299-310 abr./jun., 2016 http://www.rbspa.ufba.br ISSN 15199940

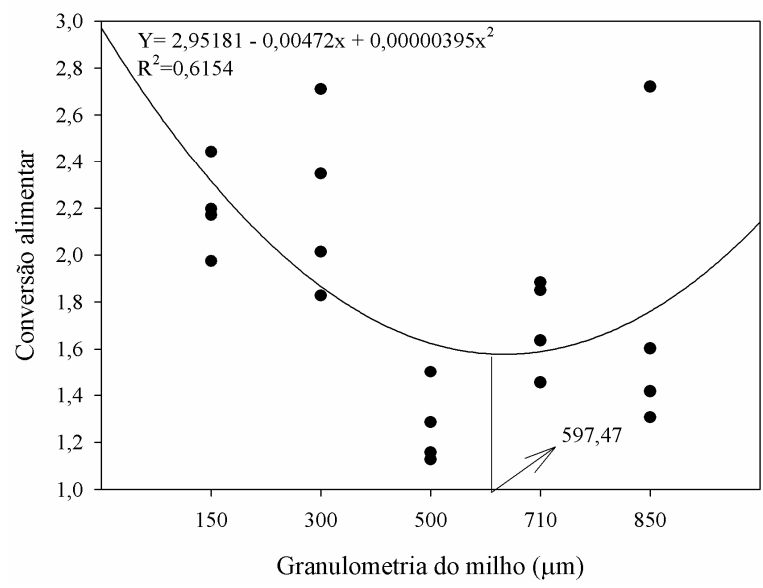

Figura 3. Efeito da granulometria do milho sobre a conversão alimentar para juvenis de tambaqui

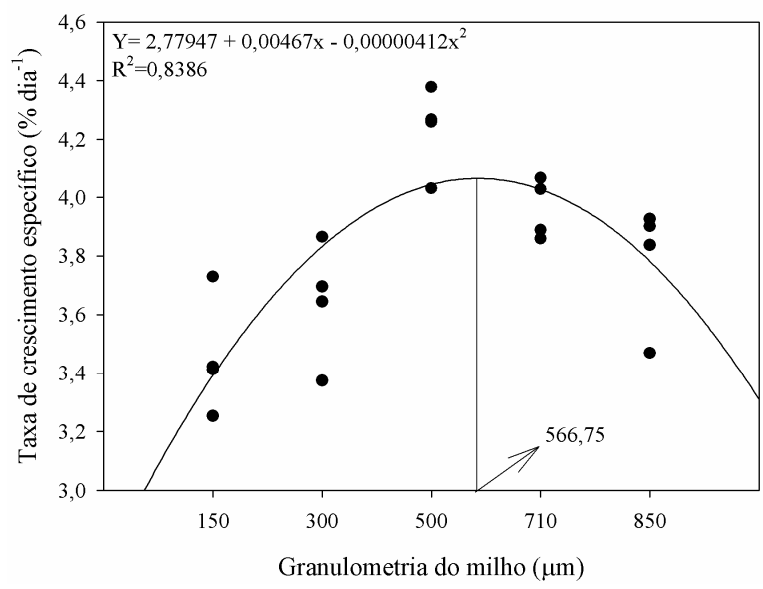

Figura 4. Efeito da granulometria do milho sobre a taxa de crescimento específico de juvenis de tambaqui

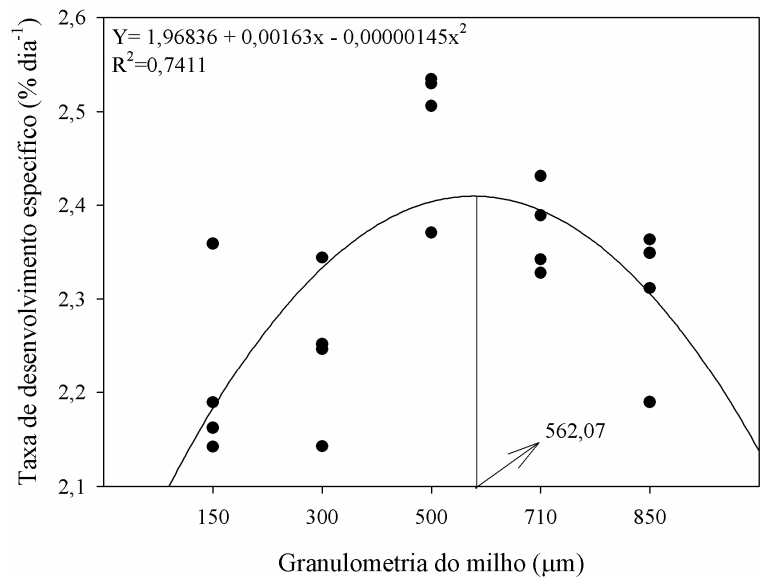

Figura 5. Efeito da granulometria do milho sobre a taxa de desenvolvimento específico de juvenis de tambaqui 
Rev. Bras. Saúde Prod. Anim., Salvador, v.17, n.2, p.299-310 abr./jun., 2016 http://www.rbspa.ufba.br ISSN 15199940

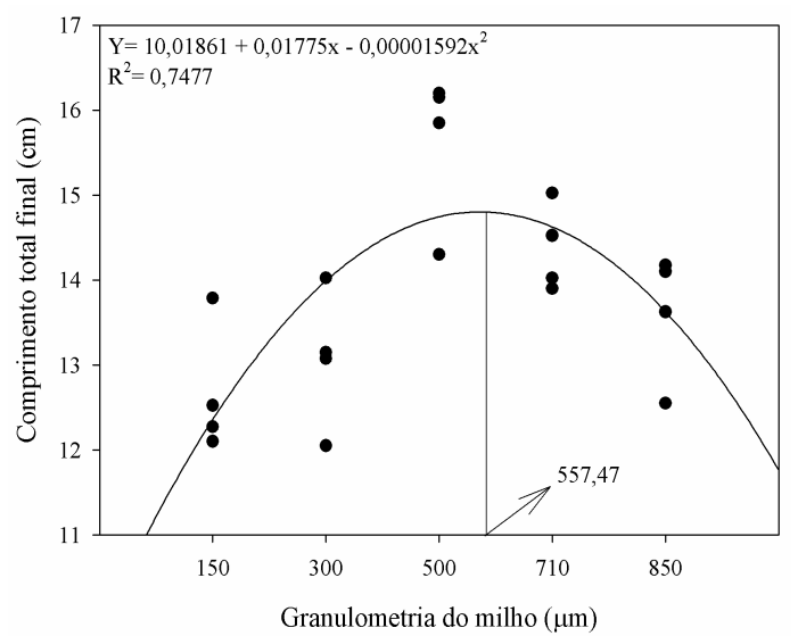

Figura 6. Efeito da granulometria do milho sobre comprimento total final de juvenis de tambaqui

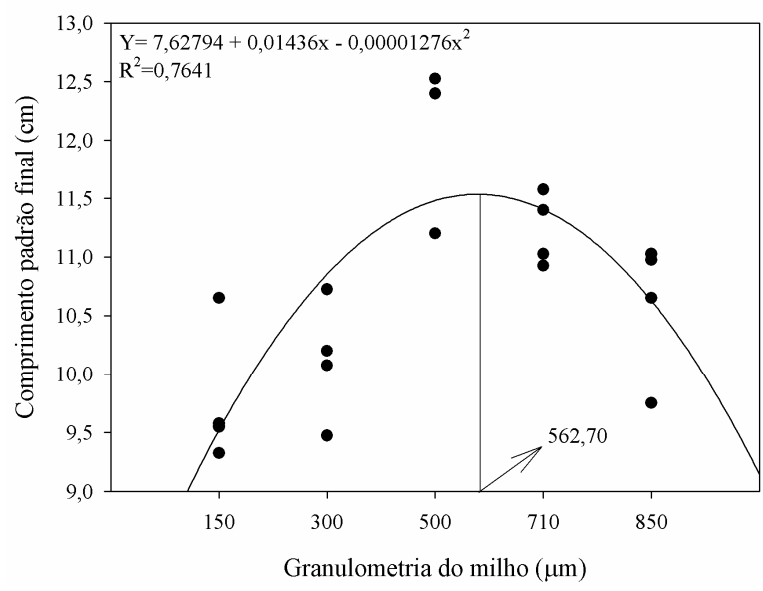

Figura 7. Efeito da granulometria do milho sobre comprimento padrão final de juvenis de tambaqui

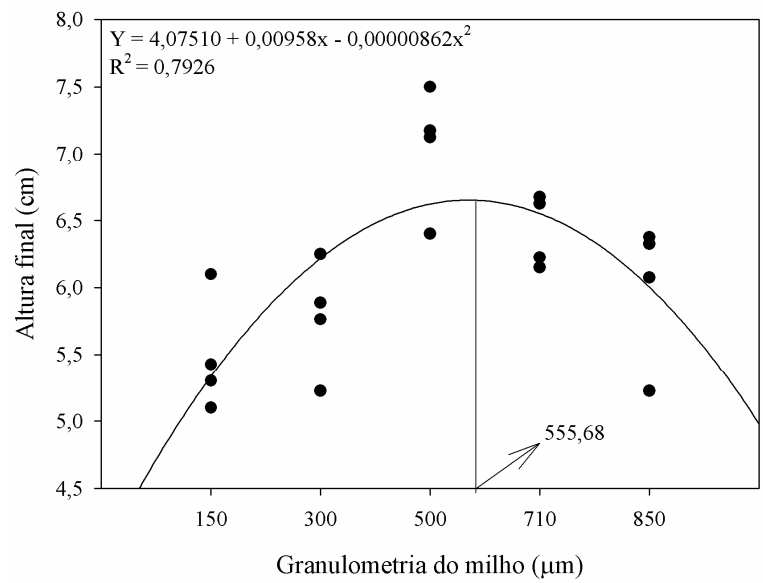

Figura 8. Efeito da granulometria do milho sobre altura final de juvenis de tambaqui 
Rev. Bras. Saúde Prod. Anim., Salvador, v.17, n.2, p.299-310 abr./jun., 2016 http://www.rbspa.ufba.br ISSN 15199940

Partículas maiores podem passar pelo trato gastrintestinal mais lentamente permitindo maior tempo para ação enzimática e, consequentemente, aumentando a disponibilidade dos nutrientes, no entanto, quanto menor a granulometria, maior a área para ação das enzimas digestivas (ZANOTTO et al., 1995; HAYASHI et al., 1999). Os resultados indicam que a granulometria do milho de $500 \mu \mathrm{m}$ pode representar o ponto de equilíbrio entre a taxa de passagem e a ação enzimática no trato digestório de juvenis de tambaqui.

Observou-se que a granulometria do milho não influenciou $(\mathrm{P}>0,05)$ a composição da carcaça de juvenis de tambaqui em relação a umidade, proteína bruta, extrato etéreo e matéria mineral (Tabela 4).

Tabela 4. Valores médios de umidade (UM), proteína bruta (PB), extrato etéreo (EE) e matéria mineral (MM) da carcaça de juvenis de tambaqui alimentados com rações contendo diferentes granulometrias de milho

\begin{tabular}{lccccccc}
\hline \multirow{2}{*}{ Variável } & \multicolumn{9}{c}{ Granulometria $(\mu \mathrm{m})$} & Valor de & $\mathrm{CV}^{1}$ \\
& 150 & 300 & 500 & 710 & 850 & $\mathrm{~F}$ & $(\%)$ \\
\hline UM & 71,78 & 71,44 & 69,87 & 70,90 & 70,88 & 1,89 & 2,51 \\
PB & 50,52 & 48,38 & 48,89 & 51,20 & 50,87 & 2,82 & 7,11 \\
EE & 32,93 & 38,30 & 33,61 & 32,22 & 32,41 & 3,51 & 9,73 \\
MM & 14,18 & 13,41 & 14,64 & 14,34 & 14,57 & 0,34 & 8,38 \\
\hline
\end{tabular}

${ }^{1} \mathrm{CV}=$ coeficiente de variação.

A composição da carcaça de peixes pode ser alterada tanto pela concentração e composição de nutrientes na ração quanto pela taxa de alimentação (SHEARER, 1994). No entanto, poucas informações estão disponíveis sobre a influência da granulometria de ingredientes de rações para peixes sobre a composição da carcaça. Semelhantemente aos resultados obtidos no presente estudo, Soares et al. (2003) não observaram efeito da granulometria dos ingredientes das rações sobre a composição de filé para a tilápia do Nilo.

Os valores de composição da carcaça obtidos são semelhantes aos encontrados em outros estudos com tambaqui (LOPES et al., 2010; OISHI et al., 2010; SANTOS et al., 2010; MENDONÇA et al.; 2012; PEREIRAJÚNIOR et al., 2013).

Embora a granulometria do milho de $500 \mu \mathrm{m}$ tenha melhorado o desempenho zootécnico e a utilização do alimento, essas alterações não foram suficientes para que houvesse mudanças nos parâmetros da carcaça dos peixes.

Verificou-se comportamento quadrático $(\mathrm{P}<0,05)$ para as variáveis custo total de produção e custo médio da ração por quilograma de peso vivo ganho, obtendo-se valores mais altos para granulometrias do milho estimadas em, respectivamente, 600,44 e $602,11 \mu \mathrm{m}$ (Figuras 9 e 10).

A ração com granulometria do milho de $500 \mu \mathrm{m}$ apresentou o melhor índice de eficiência econômica entre todos os tratamentos, enquanto o pior índice foi obtido pela ração com granulometria do milho de $150 \mu \mathrm{m}$ (Figura 11). A alimentação representa grande parte dos custos durante o cultivo de peixes, por isso, são necessárias estratégias que promovam redução dos custos e potencializem o desempenho dos peixes. 
Rev. Bras. Saúde Prod. Anim., Salvador, v.17, n.2, p.299-310 abr./jun., 2016 http://www.rbspa.ufba.br ISSN 15199940

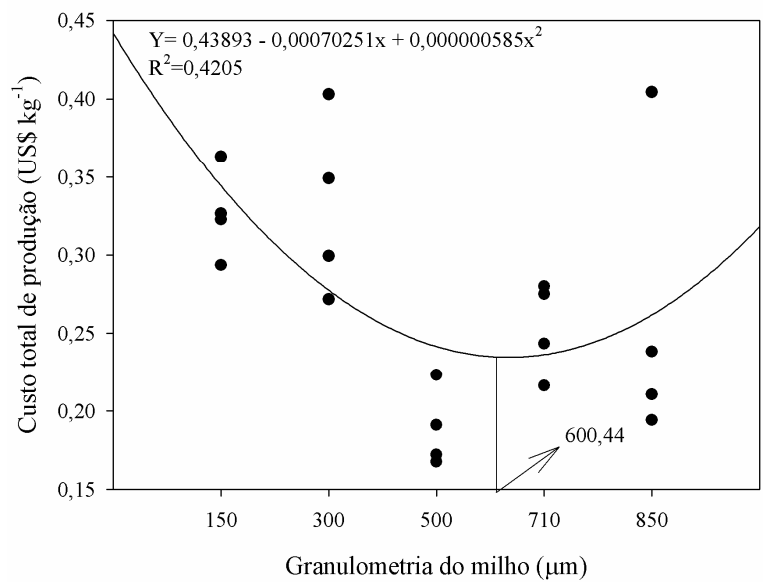

Figura 9. Efeito da granulometria do milho sobre o custo total de produção de juvenis de tambaqui

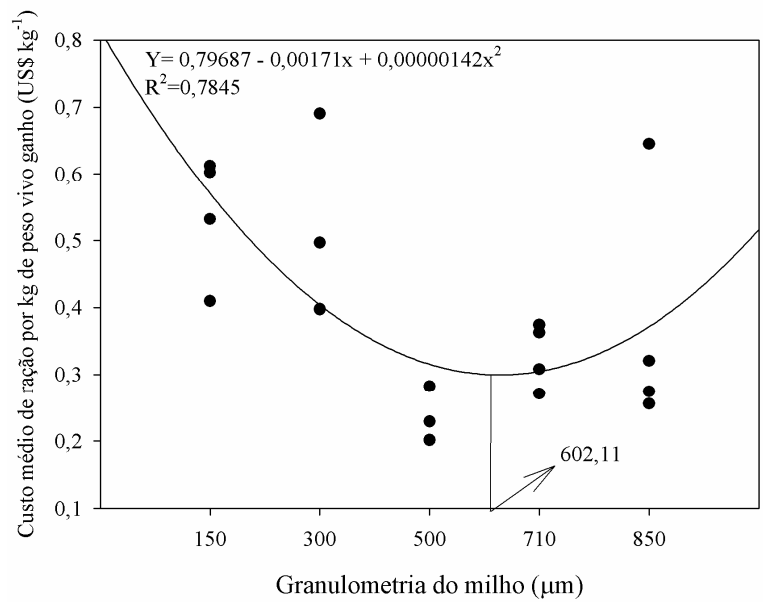

Figura 10. Efeito da granulometria do milho sobre o custo médio de ração por quilograma de peso vivo ganho de juvenis de tambaqui

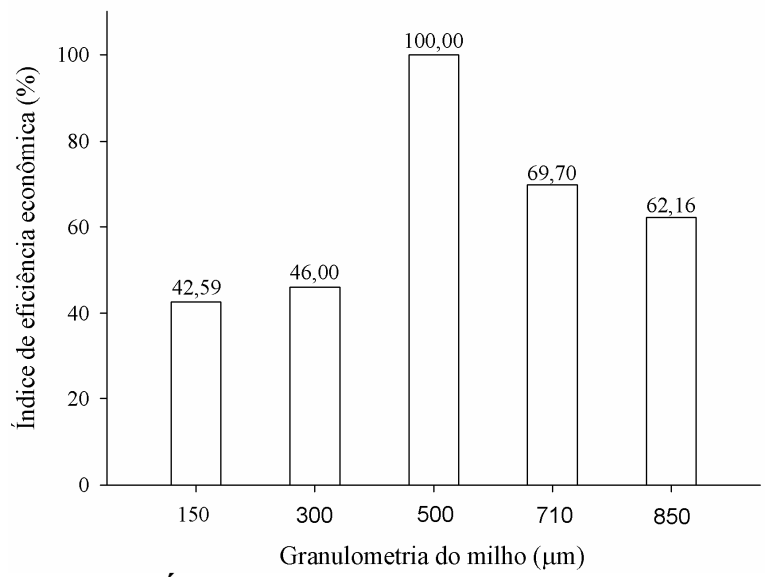

Figura 11. Índice de eficiência econômica de rações com diferentes granulometrias do milho para juvenis de tambaqui 
Rev. Bras. Saúde Prod. Anim., Salvador, v.17, n.2, p.299-310 abr./jun., 2016 http://www.rbspa.ufba.br ISSN 15199940

Em média, gastou-se 134,78 e $60,87 \%$ menos com ração para produzir um quilograma de peixe utilizando-se a granulometria do milho de $500 \mu \mathrm{m}$ comparando-se, respectivamente, às granulometrias de 150 e $850 \mu \mathrm{m}$. De igual modo, o custo total de produção foi, em média, 73,68 e $36,84 \%$ menor utilizandose a granulometria do milho de $500 \mu \mathrm{m}$ comparando-se, respectivamente, à granulometria de 150 e $850 \mu \mathrm{m}$.

Redução nos custos de produção já foi observado por diversos autores que estudaram estratégias de alterações nas rações para peixes. Por exemplo, Lemos et al. (2011) com tambaqui e Carvalho et al. (2012) com tilápia do Nilo incluindo produtos alternativos nas rações $\mathrm{e}$ Azevedo et al. (2015) e Azevedo et al. (2016) suplementando rações para, respectivamente, tilápia do Nilo e tambaqui, com prebiótico, probiótico e simbiótico observaram redução nos custos de produção e aumentos na receita bruta e lucratividade.

Os melhores índices de desempenho zootécnico e eficiência econômica obtidos mostraram a viabilidade da utilização da granulometria do milho de $500 \mu \mathrm{m}$ em rações para juvenis de tambaqui.

\section{REFERÊNCIAS}

ARAÚJO-LIMA, C.A.R; GOMES, L.C. Tambaqui, In: BALDISSEROTO, B.; GOMES, L.C. (Eds.). Espécies nativas para piscicultura no Brasil. Santa Maria, RS: UFSM, 2005. p.175-202.

ARAÚJO-LIMA, C.; GOULDING, M. Os frutos do tambaqui: ecologia, conservação e cultivo na Amazônia. Brasília: Sociedade Civil Mamirauá/CNPq, 1998. 186p.
AZEVEDO, R.V.; FOSSE-FILHO, J.C.; CARDOSO, L.D.; MATTOS, D.C.; VIDAL-JÚNIOR, M.V.; ANDRADE, D.R. Economic evaluation of prebiotics, probiotics and symbiotics in juvenile Nile tilapia. Revista Ciência Agronômica, v.46, n.1, p.72-79, 2015.

AZEVEDO, R.V.; FOSSE-FILHO, J.C.; PEREIRA, S.L.; CARDOSO, L.D.; VIDAL-JÚNIOR, M.V.;

ANDRADE, D.R. Suplementação com prebiótico, probiótico e simbiótico para juvenis de tambaqui a duas densidades de estocagem. Pesquisa Agropecuária Brasileira, v.51, n.1, p.9-16, 2016.

AZEVEDO, R.V.; TONINI, W.C.T.; BRAGA, L.G.T. Óleo e torta de dendê em rações para juvenis de tilápia-donilo. Pesquisa Agropecuária Brasileira, v.48, n.8, p.1028-1034, 2013.

BRAGA, L.G.T.; AZEVEDO, R.V.; CIPRIANO, F.S.; LIMA, K.S.; MAGALHÃES-JÚNIOR, F.O.; TONINI, W.C.T.; SANTOS, D.F. Inclusão de celulose em rações para juvenis de tambacu. Revista Brasileira de Saúde e Produção Animal [online], v.15, n.4, p.947-956, 2014.

CARVALHO, J.S.O.; AZEVEDO, R.V. de; RAMOS, A.P.S.; BRAGA, L.G.T. Agroindustrial byproducts in diets for Nile tilapia juveniles. Revista Brasileira de Zootecnia, v.41, n.3, p.479-484, 2012.

GRAEF, E.W. As espécies de peixes com potencial para a criação no

Amazonas. In: VAL, A.L.; HONCZARYK, A. (Eds.). Criando peixes na Amazônia. Manaus: INPA, 1995. p.29-43. 
Rev. Bras. Saúde Prod. Anim., Salvador, v.17, n.2, p.299-310 abr./jun., 2016 http://www.rbspa.ufba.br ISSN 15199940

GUIMARÃES, I.G.; MIRANDA, E.C.; RIBEIRO, V.L.; MARTINS, G.P.; MIRANDA, C.C. Farinha de camarão em dietas para tilápia do Nilo (Oreochromis niloticus). Revista Brasileira de Saúde e Produção Animal [online], v.9, n.1, p.140-149, 2008.

HAYASHI, C.; BOSCOLO, W.R.; SOARES, C.M.; BOSCOLO, V.R.; GALDIOLI, E.M. Uso de diferentes graus de moagem dos ingredientes em dietas para tilápia-do-nilo (Oreochromis niloticus L.) na fase de crescimento. Acta Scientiarum, v.21, n.3, p.733-737, 1999.

LEMOS, M.V.A.; GUIMARÃES, I.G.; MIRANDA, E.C. Farelo de coco em dietas para o tambaqui (Colossoma macropomum). Revista Brasileira de Saúde e Produção Animal [online], v.12, n.1, p.188-198, 2011.

LOPES, J.M.; PASCOAL, L.A.F.; SILVA-FILHO, F.P.; SANTOS, I.B.; WATANABE, P.H.; ARAÚJO, D.M.; PINTO, D.C.; OLIVEIRA, P.S. Farelo de babaçu em dietas para tambaqui. Revista Brasileira de Saúde e Produção Animal [online], v.11, n.2, p.519-526, 2010.

MAKINO, L.C.; NAKAGHI, L.S.O.; PAES, M.C.F.; MALHEIROS, E.B.; KOBERSTEIN, T.C.R.D. Diferentes granulometrias de rações sobre o ganho de peso, crescimento, sobrevivência e reversão sexual para tilápias-do-Nilo (Oreochromis niloticus). Brazilian Journal of Veterinary Research and Animal Science, v.47, n.4, p.268-273, 2010 .

MENDONÇA, P.P.; SANTOS, M.V.B.; VIDAL-JÚNIOR, M.V.; ANDRADE, D.R. Influência do fotoperíodo emeral sobre características bromatológicas da carcaça de juvenis de tambaqui. Ciência Animal Brasileira, v.12, n.2, p.213-220, 2011.
MEURER, F.; BOMBARDELLI, R.A.; HAYASHI, C.; FORNARI, D.C. Grau de moagem dos alimentos em rações para a tilápia do Nilo (Oreochromis niloticus) durante o período de reversão sexual. Acta Scientiarum. Animal Sciences, v.27, n.1, p.81-85, 2005.

NATIONAL RESEARCH COUNCIL NRC. Nutrient Requeriment of Fish. Washington, DC.: National Academy Press, 1993.

OISHI, C.A.; NWANNA, L.C.; PEREIRA-FILHO, M. Optimum dietary protein requirement for Amazonian Tambaqui, Colossoma macropomum Cuvier, 1818, fed fish meal free diets. Acta Amazonica, v.40, n.4, p.757-762, 2010.

PEREIRA-JÚNIOR, G.; BARBOSA, P.S.; SHIMODA, E.; PEREIRAFILHO, M. Composição corporal de tambaqui alimentado com rações contendo farinha de folha de leucena. Archivos de Zootecnia, v.62, n.238, p.211-216, 2013.

SANTOS, L.; PEREIRA-FILHO, M.; SOBREIRA, C.; ITUASSÚ, D.; FONSECA, F. A.L. Exigência proteica de juvenis de tambaqui (Colossoma macropomum) após privação alimentar. Acta Amazonica, v.40, n.3, p.597-604, 2010.

SAS. Statistical Analysis Systems. User's guide: Statistics. Versão 9.0. Cary: Caroline State University, 2001.

SENA, M.F.; AZEVEDO, R.V.; RAMOS, A.P.S.; CARVALHO, J.S.O.; COSTA, L.B.; BRAGA, L.G.T.

Mesquite bean and cassava leaf in diets for Nile tilapia in growth. Acta Scientiarum. Animal Sciences, v.34, n.3, p.231-237, 2012. 
Rev. Bras. Saúde Prod. Anim., Salvador, v.17, n.2, p.299-310 abr./jun., 2016 http://www.rbspa.ufba.br ISSN 15199940

SHEARER, K.D. Factors affecting the proximate composition of cultured fishes with emphasis on salmonids. Aquaculture, v.119, n.1, p.63-88, 1994.

SILVA, A.M.R.; BERTO, D.A.; LIMA, G.J.M.M.; WECHSLER, F.S.;

PADILHA, P.M.; CASTRO, V.S. Valor nutricional e viabilidade econômica de rações suplementadas com maltodextrina e acidificante para leitões desmamados. Revista Brasileira de Zootecnia, v.37, n.2, p.286-295, 2008.

SILVA, D.J.; QUEIROZ, A.C. Análise de alimentos: métodos químicos e biológicos. 3.ed. Viçosa: UFV, 2006. $235 \mathrm{p}$.

SOARES, C.M.; HAYASHI, C.; BOSCOLO, W.R.; MEURER, F. Diferentes graus de moagem dos ingredientes em dietas peletizadas para a tilápia-do-nilo (Oreochromis niloticus L.) em fase de crescimento.

Desempenho e digestibilidade aparente.

Zootecnia Tropical, v.21, n.3, p.275287, 2003.

ZANOTTO, D.L.; NICOLAIEWSKY, S.; FERREIRA, A.S.; GUIDONI, A.L.; LIMA, G.J.M.M. Granulometria do milho na digestibilidade das dietas para suínos em crescimento e terminação. Revista Brasileira Zootecnia, v.24, n.3, p.428-436, 1995.

Data de recebimento: 25/06/2015

Data de aprovação: 13/04/2016 